clear enough evidence of this. The pressure of the rapidly expanding human population makes it more urgent than ever before that we should be deeply concerned about conservation and the utilization of land to secure its highest potential for sustained productivity. The attendant need that ecological understanding should be "built into the wisdom of the human race" is really what provides the stimulus for writing this book.

Accordingly, Prof. Sears has written for the non-biologist, conveying, in his easy, friendly style, a breadth of vision and understanding that will commend the book widely. $\mathrm{He}$ illustrates his discussion with well-chosen examples drawn largely from plant biology. The biologist may feel a little disappointed that the stimulating introduction does not lead to something more detailed and precise. By following up some of the examples, the reviewer feels, the argument might have been made more forceful, yet at the same time this could upset the balance of the broad picture Prof. Sears has set out to give. There is a refreshingly wide perspective in the writing which must appeal alike to the general reader and those biologists, victims of extreme specialization, for whom plants and animals in their natural surroundings are unfamiliar and perhaps something of an anachronism.

In the teaching of biology in schools and colleges Prof. Sears urges priority for the out-of-doors as the proper laboratory in which to begin, so that the student may be "helped to see-really to see-grasses and trees, dogs and rabbits before we begin to talk to him of the marvellous self-replication of DNA or the relation of the Krebs cycle to bioenergetics". It is not that Prof. Sears is in any way seeking to put the clock back, but rather to restore perspective and a reasonable balance of emphasis, so that we may better understand the picture as a whole.

After introducing his theme in the first two chapters, and showing its relevance to problems of modern civilization, the author takes us back to the very beginning and reviews the narrow range of physical conditions, existing on this planet, which make life as we know it a possibility. $\mathrm{He}$ then sketches in some of the landmarks of biological thought, tracing the early stirrings of ecological ideas and the pioneer work which led to the emergence of ecology as a science in its own right. There follows a consideration of energy transformations and entropy, their bearing on life as seen in the individual's quest for a supply of energy and the circulation of energy and materials within a natural community; next some discussion of the classification of living things and the individual; then a short review of the contributions of water, rocks and soil to the living landscape. In the final two chapters, entitled "The Historical Factor" and "Reading The Landscape", the author rounds off what is a scholarly book, leaving the reader much to think about. MaURICE AsHBY

\section{ELASTIN AND ELASTASE}

Elastolysis and Ageing

By David A. Hall. ( $\AA$ Monograph in the Bannerstone Division of American Lectures in Geriatries and Gerontology.) Pp. xiii + 160. (Springfield, IIl.: Charles C. Thomas, 1964.) 6.75 dollars.

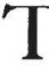

HE fibrous proteins of connective tissue comprise more than 40 per cent of the total body protein in mammals, and it is not surprising that the structure of collagen and elastin and its change with age have been investigated extensively. Over the past ten years or more many chemists and physicists have found it more profitable to direct their attention to collagen and much is now known of its structure, but recently there has been a resurgence of interest in elastin. As detailed investigations reveal more precise information about its structure, no doubt attempts will be made to relate this new information to the behaviour of elastin-containing tissues in vivo, particularly to changes accompanying ageing and the development of pathological conditions in the cardiovascular system. There is, however, a substantial gap between results of in vitro investigations on highly purified elastin and its behaviour in its very complex natural environment. Dr. Hall's book, therefore, appears at a very appropriate time, for it deals primarily with the interactions between elastic tissues and some of the agents they might be expected to encounter in vivo, in particular with enzymes of the elastase complex and their inhibitors.

Dr. Hall and his colleagues have been active in this field for a number of years, and Elastolysis and Ageing is, to a large extent, an account of their efforts. He has been led to the view that several of the features of vascular degeneration and atherosclerosis may be attributed to the interaction of the elastase enzyme system with elastic fibres, and here he attempts the onerous task of presenting a unified picture of these diverse phenomena.

The book is divided into four main sections. The first deals with the structure of elastic fibres and includes discussion of the properties of solubilized elastins and their possible relation to elastin fibrogenesis. Most of this section, however, is concerned with the evidence for a two-component structure of the elastic fibre, consisting of a protein core surrounded by a 'sheath' consisting of protein, polysaccharide and also probably lipid. Much of this evidence arises from experiments in which elastase was used as a 'structural probe', and the second, and largest, section describes the preparation and properties of this pancreatic enzyme. Hall, and more recently other workers, have recognized that this enzyme system contains two distinct enzymes which interact with elastic fibresa proteolytic enzyme (elastoproteinase elastase) and a second enzyme which has a synergistic effect on the first and according to Hall and his colleagues is a lipoproteinase. The evidence for their existence and mode of action is discussed in detail together with the similarity of the lipoproteinase and the lipoproteinase of post-heparin clearing factor. The third section is devoted to the nature and mode of action of elastase inhibitors occurring in serum and elastic tissues.

Dr. Hall has drawn together all these facets of an extremely complicated situation into a unified picture in which the normal functioning of the blood vessel walls depends on a delicate balance of the effects of the several enzymes and inhibitors. The way in which this balance may be disturbed in ageing is indicated in the final chapter. In achieving this he has put forward several controversial hypotheses which attribute a key role to the mucoproteinlipid complex of elastic fibres. This is regarded as being responsible for the binding of elastoproteinase to the fibres, for the binding of lipid and as a substrate for elastolipoproteinase. The need for caution in interpreting results obtained with highly purified elastin in terms of functional changes is thus emphasized.

The standard of presentation of the book is high, though there are a number of typographical errors, particularly in the description of some of the tables and figures, and some references have been omitted. G. C. Woon

\section{ULTRASOUND IN SURGERY}

Ultrasound as a Diagnostic and Surgical Tool

Edited by Dr. Douglas Gordon. (Based on the International Symposium held at the Royal College of Surgeons, London, December 5th and 6th, 1962.) Pp. xii +413 . (Edinburgh and London: E. and S. Livingstone, Ltd., 1964.) 63s. net.

THE task of editing a symposium is not an easy one, since the individual contributions do not necessarily come together as a complete account of the subject, and may occasionally represent facets, the growing points in the estimation of some but not necessarily of others. Dr. 